\title{
Emu Oil
}

National Cancer Institute

\section{Source}

National Cancer Institute. Emu Oil. NCI Thesaurus. Code C107305.

An oil rendered from the fat of the emu, Dromaius novaehollandiae. Emu oil is used for its anti-inflammatory and wound healing properties. 